\title{
Corrigendum
}

\section{Is There an Age Pattern in the Treatment of AMI? Evidence from Ontario-Corrigendum}

\section{Michel Grignon, Byron G. Spencer, and Li Wang McMaster University}

doi:10.1017/S0714980810000383, published by Cambridge University Press, 9 September 2010

There are two errors in figure legends in the article by Grignon et al. in the September 2010 issue of Canadian Journal on Aging:

The time frame in the legend for Figure 1 is incorrectly listed as 1995-2000. The correct time frame is 1995-2005. In Figure 3, the note below the figure legend incorrectly indicates that "Proportions are relative to age group 40-49." The figure is not related to the 40- to 49-year age group, and the note should not have been added.

Figures 1 and 3, with their correct legends, appear below:
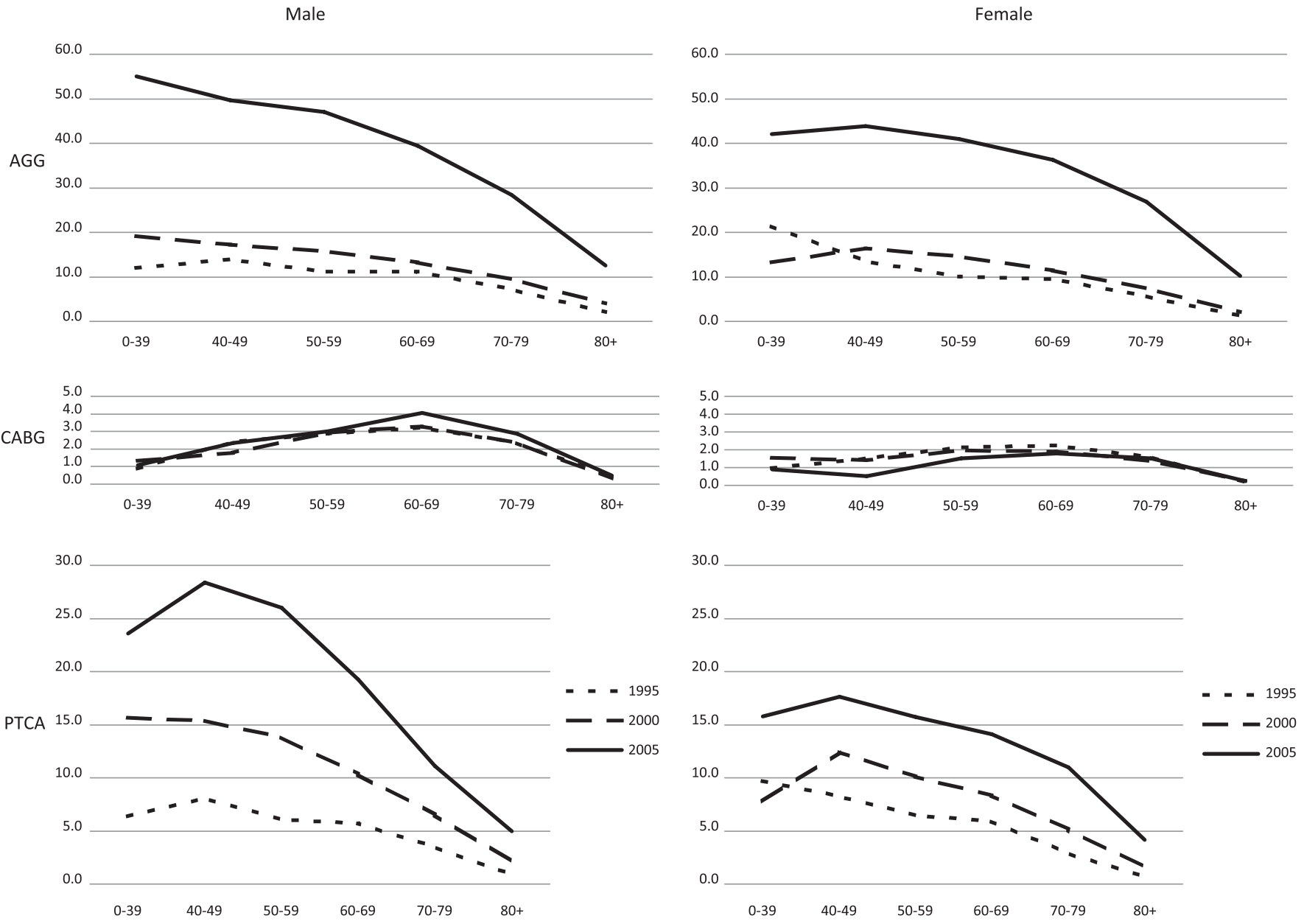

Figure 1: Observed Percentages of AMI Admissions Receiving Specified Treatments, by Age and Sex, All Hospitals, Ontario, 1995-2005.

Canadian Journal on Aging / La Revue canadienne du vieillissement 29 (4) : 593-594 (2010) 

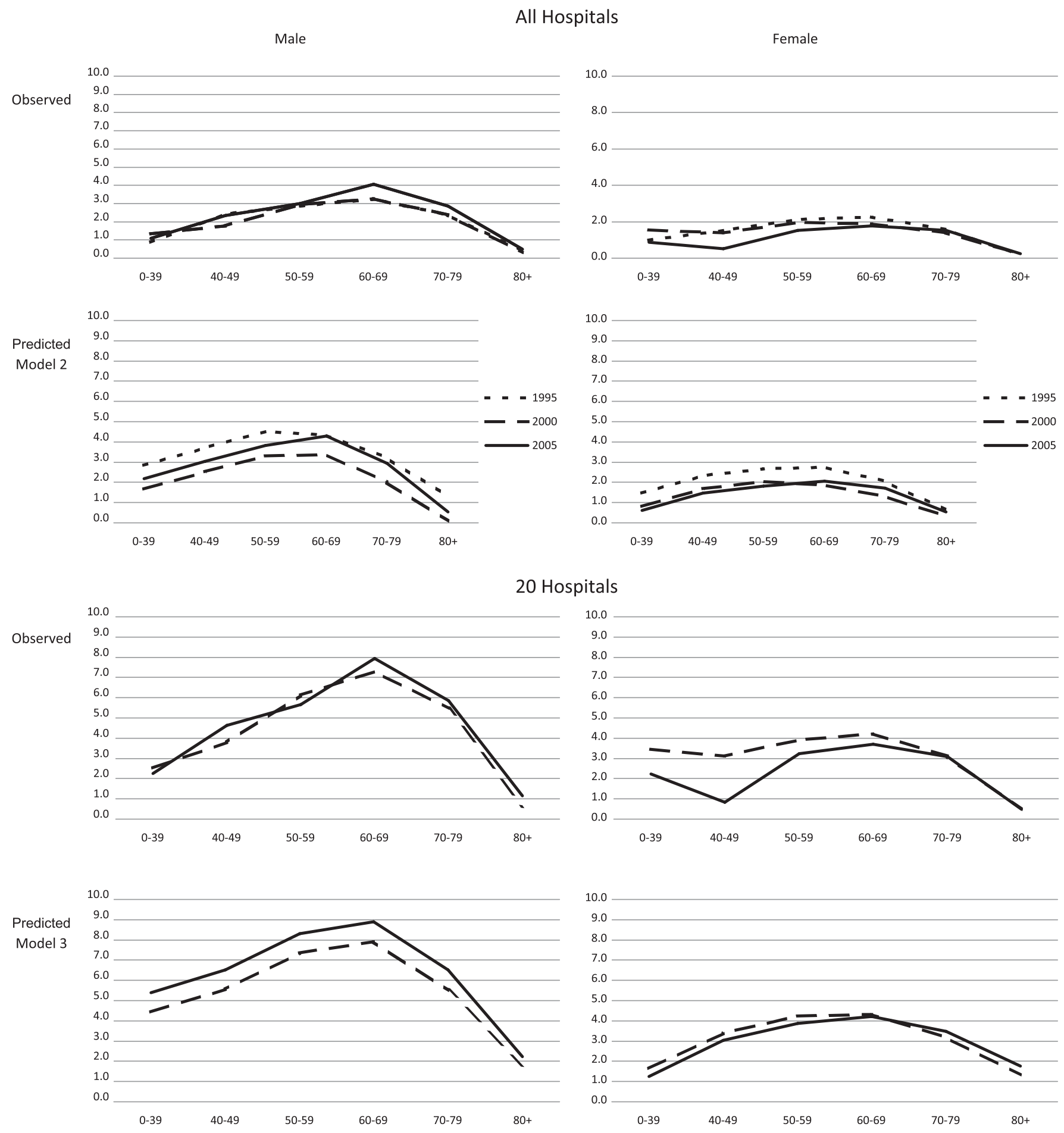

Figure 3: Observed and Predicted Proportions of AMI Admissions Receiving CABG, All Hospitals and 20 Hospitals with most AMI Admissions, Ontario, 1995-2005.

\section{Reference}

Grignon, M., Spencer, B.G., \& Wang, L. (2010). Is There an Age Pattern in the Treatment of AMI? Evidence from Ontario. Canadian Journal on Aging, 29(3), 317-332. doi:10.1017/S0714980810000383. 